\title{
Papers
}

\section{Value at risk, GARCH modelling and the forecasting of hedge fund return volatility}

\author{
Roland Füss", Dieter G. Kaiser and Zeno Adams \\ *Department of Empirical Research and Econometrics, University of Freiburg, \\ Platz der Alten Synagoge, Freiburg im Breisgau, D-79085, Germany. \\ Tel: + 490761203 2341, Fax: + 490761203 2340, \\ E-mail: roland.fuess@vwl.uni-freiburg.de
}

Received (in revised form): 29th August, 2006

\begin{abstract}
Dr Roland Füss is Lecturer at the Department of Empirical Research and Econometrics and Assistant Professor at the Department of Finance and Banking at the University of Freiburg, Germany. He holds an MBA from the University of Applied Science in Lörrach, M.Ec. and PhD degree in Economics from the University of Freiburg. His research interests are in the field of applied econometrics, alternative investments as well as international and real estate finance. He has (co-) authored several articles in finance journals and book chapters. Further, he is a member of the Verein für Socialpolitik and of the German Finance Association.
\end{abstract}

Dieter G. Kaiser is responsible for the institutional research at Benchmark Alternative Strategies in Frankfurt, Germany. He has worked for Dresdner Kleinwort Wasserstein and Crédit Agricole Asset Management in Frankfurt where he was responsible for the fund-of-hedge-funds Marketing Support. He has written several articles on the subject of alternative investments that have been published in professional as well as academic journals. He is the co-author and co-editor of five books on alternative investments published by John Wiley \& Sons, Risk Books and Gabler. He holds a Diploma in Business Administration and a Master of Arts in Banking \& Finance from the HfB Business School of Finance and Management in Frankfurt, where he has also lectured on alternative investments since 2003.

Zeno Adams is Research Assistant at the Department of Empirical Research and Econometrics, University of Freiburg, Platz der Alten Synagoge, D-79085 Freiburg im Breisgau, Germany.

\section{Practical applications}

The Value at Risk (VaR) approach is widely used within the asset and risk management of traditional and alternative investments. From the investor's point of view, an adequate VaR model should indicate how the positions of the hedge fund portfolio should be sized for the best protection against downside risk. Due to the skewness and excess kurtosis of daily financial return distributions, the normal $\mathrm{VaR}$ has its drawbacks particularly when it is applied to hedge funds. In addition to the Cornish-Fischer $\mathrm{VaR}$, which explicitly accounts for non-normally distributed returns, we examine the conditional volatility characteristics of daily hedge fund management style returns. The inclusion of time-varying conditional volatility into the $\mathrm{VaR}$ measurement enables us to trace the actual return process more effectively. We show that such a GARCH-type VaR is a superior measure of downside risk, especially for trading strategies that exhibit negative skewness and excess kurtosis and offer daily pricing.

Journal of Derivatives \& Hedge Funds, Vol. 13 No. 1, 2007, pp. 2-25 (C) 2007 Palgrave Macmillan Ltd $1753-9641 \$ 30.00$ 


\section{Abstract}

This paper examines the conditional volatility characteristics of daily management style returns and compares the out-of-sample forecasts of different Value at Risk (VaR) approaches, namely, the normal, Cornish-Fisher (CF), and the so-called GARCHtype VaR. The examination of the conditional volatility of hedge fund styles and composite returns shows important differences concerning persistence, mean reversion and asymmetry in the period under consideration. Hedge fund returns exhibit significant negative skewness and excess kurtosis, which cannot be captured in the normal VaR whereas the CF-VaR results in a systematic downward shift of the conventional VaR. The GARCH-type VaR, however, includes the time-varying conditional volatility and is able to trace the actual return process more effectively. Since the forecast performance cannot detect which of the three VaR types can match the time-varying risk adequately, an adjusted hit ratio takes the size of the hits as well as the average VaR into account. According to this, the GARCH-type VaR outperforms the other VaRs for most of the hedge fund style indices.

Journal of Derivatives \& Hedge Funds (2007) 13, 2-25. doi:10.1057/palgrave.dutr.1850048

Keywords: hedge funds; Value at Risk; GARCH models; forecasting

\section{INTRODUCTION}

Since the breakdown of Long Term Capital Management (LTCM), risk management and the transparency of hedge funds have become dramatically important and evolved into outstanding fields for practitioners and academic researchers. Value at Risk (VaR) is one of the most important concepts widely used for risk management by banks and financial institutions.
Since VaR can be easily computed by capturing risk in only one figure, it has gained increasing popularity in the past. Although there are several forms of financial risk, we focus on market risk in this paper, that is, the unexpected changes in stock returns.

The literature on VaR has become quite expansive (eg Hendricks ${ }^{1}$, Beder ${ }^{2}$, Marshall and Siegel $^{3}$ ). However, the conventional VaR assumes that returns follow a normal or conditional normal distribution. Particularly, in the case of skewed and fat-tailed returns, the assumption of normality leads to substantial bias in the VaR estimation and results in an underestimation of volatility.

In contrast to mutual funds, different trading instruments, such as arbitrage, leverage and short selling, characterise hedge funds. These trading instruments are highly dynamic and often exhibit low systematic risk (Fung and $\mathrm{Hsieh}^{4}$ ). Since hedge funds use options or option-like trading strategies or strategies that lose money during down-market phases, they may generate non-normal payoffs. In addition, Liang ${ }^{5}$ emphasises the higher Sharpe ratios and lower market risk as well as the higher abnormal returns of hedge funds investments. Moreover, it has been well documented that monthly return distributions of most hedge fund indices show extremely high negative skewness, positive excess kurtosis and, significantly, positive firstorder serial correlation. In the context of the frequently used mean-variance approach, these return properties inevitably result in an underestimation of the true volatility.

Favre and Galeano ${ }^{6}$ suggest a modified method of VaR by implementing a CornishFisher (CF) expansion, which is used to control for skewness and kurtosis. ${ }^{7}$ Agarwal and Naik ${ }^{8}$ introduce a mean-conditional $\mathrm{VaR}(\mathrm{CVaR})$ 
framework that explicitly accounts for negative tail risk. ${ }^{9}$ As the conventional VaR refers only to the frequency of extreme events, the CVaR focuses on both frequency and size of losses in the case of extreme events. Kellezi and Gilli ${ }^{10}$ introduce a risk capital measure based on the Extreme Value Theory (EVT). The EVT focuses only on extreme values, that is, the tail of the distribution, rather than the whole distribution. However, Danielsson and de Vries ${ }^{11}$ show that the EVT can be accurately used only for very extreme events and often does not provide good results at more conventional 5 per cent VaR levels. Furthermore, EVT assumes an identically and independently distributed (iid) framework that is not consistent with most financial data.

In this paper, we use a GARCH-type VaR by modelling and forecasting conditional volatility, using GARCH and EGARCH, and then implementing the time-varying volatility in the VaR. In doing so, we also control for skewness and kurtosis. Volatility forecasting is important not only in risk management and market timing for single hedge funds, but also in the context of portfolio diversification including hedge funds. The knowledge of future volatilities allows portfolio managers to control the risk temporally, for example, sell an asset or portfolio before a dramatic increase in volatility takes place (Engle and Patton ${ }^{12}$ ). Furthermore, by means of information on the volatility process in general, and the development of volatility in particular, the risk pricing of the market can be determined.

To our knowledge, there are no empirical studies that introduce GARCH-type forecasts into the conventional VaR framework to simultaneously account for time-varying volatility, serial correlation, skewness and kurtosis in hedge fund returns.
This paper is organised as follows: Firstly, the next section describes different hedge funds strategies from the data provider, Standard EPoor's, according to the different management styles. The concepts of conventional VaR and $\mathrm{CF}$ expansion are then briefly introduced. Following this, the stylised facts of volatility and the two conditional volatility models, $\operatorname{GARCH}(p, q)$ and $\operatorname{EGARCH}(p, q)$, that should capture these features are discussed.

Subsequently the conditional variances for the hedge funds styles under consideration are estimated using alternative model specifications, and their volatility characteristics are analysed. The GARCH-type models are then applied to estimate the daily VaR of the different hedge fund styles. The accuracy of one-step-ahead VaR forecasts is evaluated by different ratios that measure the distance between the observed and forecasted VaR values. Some concluding remarks are offered in the final section.

\section{HEDGE FUNDS STYLES AND THEIR STRATEGIES}

Investment strategies used by hedge funds tend to be quite different from those of traditional mutual funds. Basically, every hedge fund embarks on its own preferred strategy, which leads to a very heterogeneous asset class 'hedge funds'. However, hedge funds may be classified into a number of different strategy groups depending on the main type of strategy followed (Kat and $\mathrm{Lu}^{13}$ ). In referring to market exposure as classification criteria, Purcell and Crowley ${ }^{14}$ distinguish between three different styles of hedge funds. These broader categories encompass the relative value, the event-driven and the opportunistic strategy. Based on market exposure to traditional asset classes, Agarwal and Naik ${ }^{15}$ also classify 


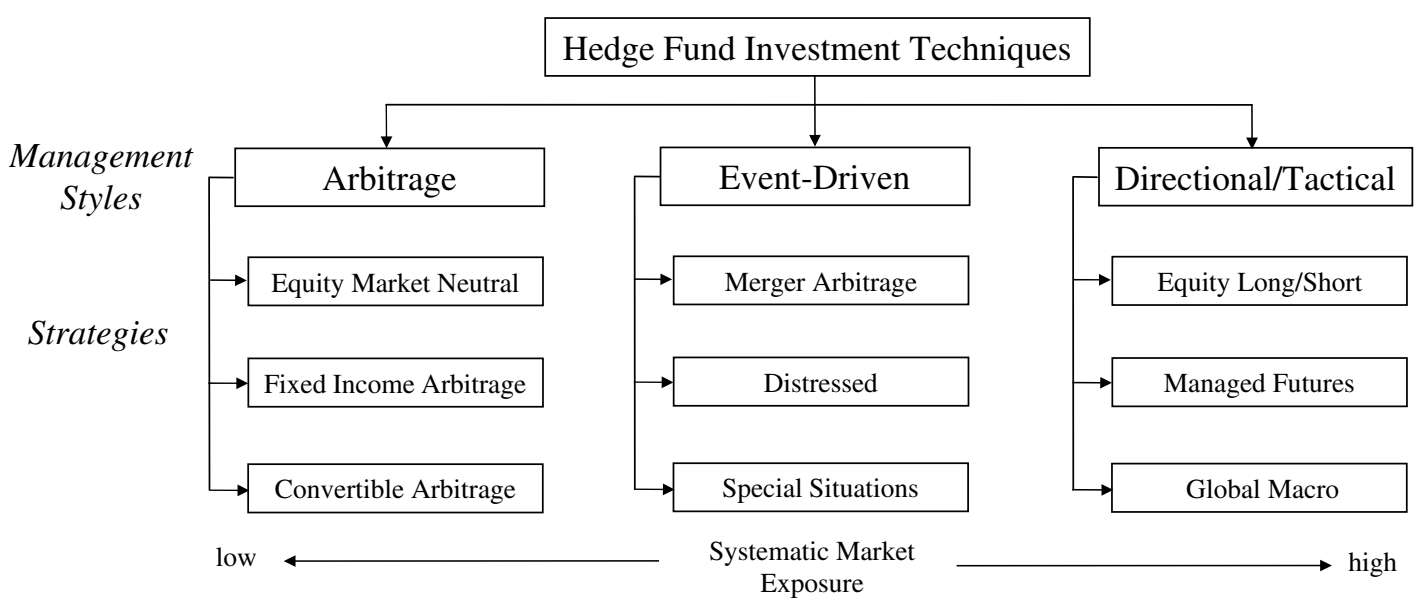

Figure 1: Hedge fund styles and strategies

Source: Adapted from Ineichen ${ }^{16}$

hedge fund strategies into categories: directional and non-directional. Ineichen ${ }^{16}$ conducts a subdivision on the hedge funds styles: arbitrage, event-driven and directional (see Figure 1). In this study, we adapt the classification proposed by the latter to match the system of the hedge funds index provider S\&P, as we use their indices later in the empirical section of this paper.

\section{Arbitrage management style}

The 'arbitrage' strategies, also known as 'relative value' or 'non-directional' strategies, try to take advantage of temporarily wrong valuations between different financial instruments and attempt to offer their investors very low market exposure. Independent of the market situation, the strategy aims at achieving absolute returns by avoiding or reducing market (beta) risk, industry risk, interest rate risk (duration), etc. Thus, this so-called 'equity market neutral' strategy takes advantage of short-term pricing inefficiencies between stocks or groups of stocks, which usually behave identically. In applying this mean-reverting strategy, the directional market risk is eliminated or neutralised as far as possible so that the beta of the overall situation is ideally zero. Capocci's ${ }^{17}$ analysis comes to the conclusion that most of the market neutral funds are not significantly exposed to the equity market, but tend to be more exposed during bear market than during bull market without being negatively impacted.

The strategy 'convertible arbitrage' exploits the differences in the value between a convertible bond and the underlying stock. It does this by buying (selling) the underrated (overrated) convertible bond and, at the same time, also selling (buying) the stock. Agarwal et al. ${ }^{18}$ show that the key risk factors in convertible arbitrage strategies are: equity (and volatility) risk, credit risk and interest rate risk. They also demonstrate that the risk-adjusted returns of convertible arbitrage hedge funds are affected by mismatches between supply of and demand for convertible bonds. They also show that convertible arbitrageurs escape some of the losses experienced by long-only convertible bond mutual funds by changing their risk exposures in response to the LongTerm Capital Management (LTCM) crisis. 
'Fixed income arbitrage' funds search for false valuations or anomalies of bonds in order to achieve arbitrage profits in securities of different maturities, credit ratings and volatilities (with high leverage factors). The overall situation should have a duration of zero, that is, the interest rate risk should be neutralised (immunisation). The advantage of this strategy is the attainment of liquidity and credit risk premiums. Leverage is also applied to increase absolute returns. ${ }^{19}$ Fung and Hsieh, ${ }^{20}$ as well as Jaeger and Wagner ${ }^{21}$ show that the fixed income arbitrage strategy bears a risk profile similar to a short option, with a risk of significant losses but otherwise steady returns. They also demonstrated that the heaviest losses of fixed income arbitrage occur in 'flight to quality' scenarios, when credit spreads suddenly widen, liquidity evaporates and emerging markets fall sharply. In their analysis of the risk and return characteristics of fixed income arbitrage strategies, Duarte et al. ${ }^{22}$ find that these tend to produce significant alphas after controlling for traditional bond and equity market risk factors. Furthermore, even after taking into account the typical hedge fund fees, these alphas remain significant, and some fixed income arbitrage strategies actually produce positively skewed returns.

\section{Event-driven management style}

The goal of the 'event-driven' strategy is to take advantage of price anomalies triggered by pending or upcoming firm transactions such as mergers, restructurings, liquidations and insolvencies. The success of this strategy comes from a false judgement of the situation and the uncertainty of other investors in the case of takeovers, reorganisations or management buyouts.
'Merger arbitrage' invests simultaneously in long and short positions by purchasing the stocks of the company being taken over and at the same time, selling those of the take-over company. Generally, stocks that are the object of a takeover gain in value while stocks of the take-over company fall in value. According to Mitchell and Pulvino, ${ }^{23}$ merger arbitrage strategies display rather high correlations to the equity markets when the latter declines and, in turn, display low correlations when stocks trade up or sideways. In other words, the payout profile of merger arbitrage strategies corresponds directly to a short position in a put option on announced merger deals.

The sub-strategy 'distressed securities' invests in assets of companies that have financial or operational problems, are bankrupt or are expecting such an economic situation. Such a situation means reorganisation, insolvencies, liquidations and/or other restructurings of companies. A typical strategy is to buy the stocks with a realised backwardation that results from the tight situation. The stocks are then kept until the process of restructuring is completed and the value of the company has appreciated.

Depending on the style of the fund manager, investments are made in bank or corporate loans, pecuniary claims, equity shares, preference shares and warrants. The risk factors of distressed securities strategies come with a simple set of exposures to credit, equity (particularly small cap equity) and liquidity risks. Jaeger and Wagner ${ }^{21}$ show that with an alpha between 3 and 4 per cent per annum, distressed securities funds and its peers in the event-driven discipline offer the highest level of alpha in the hedge fund industry.

The success of the 'special situations' strategy results from the ability to correctly judge and take advantage of a broad range of corporate 
events such as spin-offs, index reshufflings, insolvency reconstruction and share buy-backs.

This strategy also includes closed-end fund arbitrage, which involves the purchase and hedging of closed-end funds that may be trading at significantly different levels of their net asset values (NAVs).

\section{Directional/tactical management style}

The directional management styles, which are characterised by significant market exposure (long and short), contain the strategy indices equity hedge, commodity trading advisors (CTAs)/managed futures and global macro. 'Equity hedge' or 'long/short' equity funds are basically comprised of long positions in stocks that are hedged at any time through tactical short selling and/or stock index options. Most equity hedge funds have a long bias (Kat and $\mathrm{Lu}^{13}$ ). Besides stocks, equity hedge funds can also be invested in other assets on a limited scale. According to Fung and Hsieh ${ }^{24}$ as well as Jaeger and Wagner, ${ }^{21}$ most of the equity hedge managers have exposure to both the broad equity market and, in particular, to small cap stocks. They argue that it may be easier for equity hedge managers to find opportunities in a rising market, and to go short in large cap stocks and buy small ones instead.

'Managed futures' funds take long and short positions in liquid and listed futures contracts, for example, foreign exchange, interest rates, stock market indices and commodities. Most of the CTAs pursue a trend following strategy in which a trend is replicated to where one can earn from increasing as well as decreasing prices. The results of Schneeweis and Spurgin ${ }^{25}$ indicate that the technical trading rule and market momentum variables explain a significant part of the sources of managed futures funds returns. According to Jaeger and Wagner, ${ }^{21}$ 'managed futures' hedge fund strategy is the only one that displays a negative alpha. Fung and $\mathrm{Hsieh}^{26}$ show that the returns of trend following funds during extreme market shifts can be explained by a combination of primitive trend following strategies on currencies, commodities, threemonth interest rates and US bonds, but not by strategies on stock indices. $\mathrm{Kat}^{27}$ shows that when investors account for 'managed futures' in conventional portfolios, this allows them to achieve a very substantial degree of overall risk reduction at limited costs. The author concludes that adding managed futures to a portfolio of stocks and bonds reduces a portfolio's standard deviation more efficiently than other hedge funds strategies do, without the undesirable sideeffects of skewness and kurtosis. In relevant literature, for example, Schneeweis and Spurgin, ${ }^{28}$ Schneeweis, ${ }^{29}$ Ineichen, ${ }^{16}$ Kat,${ }^{27}$ Lamm, ${ }^{30}$ considered managed futures or CTAs are as a separate alternative investment class rather than as a hedge fund strategy. However, as some index providers, for example, Barclay, CS/Tremont, Eurekahedge or S\&P, also publish a managed futures strategy index, this strategy is also considered in our analysis as well.

The strategy of 'global macro' is based on macroeconomic top-down analysis, where fund managers try to profit from major economic trends and events in the global economy. Typically, large shifts in interest rates, currency, bonds and equity prices are quickly utilised by making extensive use of leverage and derivatives $\left(\right.$ Kat and $\mathrm{Lu}^{13}$ ). Jaeger and Wagner ${ }^{21}$ show that global macro managers do better in strong bond markets, have exposure to the risk characteristic of managed futures and also have some nonlinear exposure to the broad equity market. 


\section{CONVENTIONAL VAR AND THE CF EXPANSION}

The VaR is a downside risk measurement used widely by financial institutions for internal and external purposes, with the attractive

characteristics of expressing the risk in only one figure. It is the estimated loss of an asset that within a given period, normally 1 or 10 days, will only be exceeded by a certain small probability $\theta$ (mainly 1 or 5 per cent). Thus, with a probability of 95 per cent, the one day 5 per cent VaR shows the negative return that will not be exceeded within this day:

$$
\operatorname{prob}\left[\operatorname{return}_{t}<-\operatorname{VaR}_{t} \mid \Omega_{t}\right]=\theta
$$

where $\Omega_{t}$ denotes the information set available at time $t$.

Statistically speaking, the 5 per cent quantile of the probability density function of the asset returns is considered. Assuming that the returns are normally distributed under a foregoing observation period of one year, the $\mathrm{VaR}$ can be calculated as the deviation of the value from the distribution function $\eta$ times the standard deviation $\sigma$ from its mean $\mu$ :

$$
V a R=-(\eta \cdot \sigma-\mu)
$$

In general, a higher probability value and a longer period increase the $\mathrm{VaR}$. Hence, in this paper, a period of one day and a probability of 95 per cent are assumed.

The VaR is based on the assumption of normally distributed returns. However, financial asset and particularly hedge fund returns often feature excess kurtosis and negative skewness, which make the probability of extreme returns more likely than under a normal distribution. Thus, applying the VaR under the assumption of normality can lead to a systematic underestimation of the actual risk. Favre and Galeano ${ }^{6}$ apply a CF expansion by adjusting the critical value according to the distribution function $\eta$ :

$$
\begin{gathered}
\eta_{C F}=\eta+\frac{1}{6}\left(\eta^{2}-1\right) S+\frac{1}{24}\left(\eta^{3}-3 \eta\right) \\
K-\frac{1}{36}\left(2 \eta^{3}-5 \eta\right) S^{2}
\end{gathered}
$$

with $S$ and $K$ as the skewness and the excess kurtosis of the empirical distribution, respectively. If the return distribution is normal, that is, $S$ and $K$ are equal to zero, then $\eta_{C F}=\eta$ according to equation (2). In contrast, for non-normally distributed hedge fund returns, it can be expected that the VaR threshold obtained from CF expansion will be more accurate in comparison with the estimated threshold from conventional $\mathrm{VaR}$.

\section{MODELS OF CONDITIONAL PRICE VOLATILITY}

Generally speaking, a volatility model has to be able to forecast the variance of a time series of returns preferably well. Thus, to forecast the quantiles for VaR applications, the predictability of volatility is required. Engle and Patton ${ }^{12}$ mention common stylised facts of asset price volatility process that should also hold for hedge fund prices. Many of these stylised facts can be viewed as properties of the volatility forecasts, and can be taken as a starting point when examining its consistency with the time series data.

If current returns or current volatility shocks have an influence on the expected variance several periods in the future, then the volatility process of returns is called persistent. This property is based on the observation of volatility clustering in the price process whereupon clusters of high and low price changes occur over time. Mandelbrot ${ }^{31}$ and Fama ${ }^{32}$ empirically conclude that large stock price changes are often 
followed by large price variation, and there are periods in which one can observe consecutive small changes.

Volatility is referred to as mean reverting (or stationary) if, after a period of high or low volatility, a reversion to a normal level of risk eventually occurs over time. Mean reversion of volatility is thus regarded as the normal level of volatility that is always reached after short-run deviations. In this way, the conditional variance fluctuates around the unconditional volatility depending on positive and negative differences.

Many volatility models assume that the variance of asset prices is influenced asymmetrically by positive and negative innovations. Hence, it is very unlikely that positive and negative shocks have the same effect on the conditional volatility of assets or hedge fund returns. The influence of the sign of the price innovation on volatility, and the negative correlation between asset returns and changes in volatility, is called leverage effect or risk premium effect. The leverage effect describes the circumstance when decreasing stock prices increase the debt to equity ratio which, in turn, results in a higher volatility of returns for shareholders. The risk premium effect suggests that increased volatility caused by news reduces the demand for the stock because of risk-averse market participants (Engle and Patton ${ }^{12}$ ). Besides purely endogenous effects, which are normally considered in univariate volatility models by only using information from the history of a time series, other exogenous factors (like interest rates, exchange rates, etc.) and/or deterministic events (like announcements by companies, economic news, time-of-day effects, etc.) can be relevant for the volatility of a time series (Bollerslev and Melvin, ${ }^{33}$ Engle et al., ${ }^{34}$ Engle and Mezrich ${ }^{35}$ ).

\section{$\operatorname{GARCH}(p, q)$ model}

The conditional mean $\mu_{t}$ and the conditional variance $h_{t}$ of a time series of returns $R_{t}$ are defined as the mean and the variance of a random variable with their expectation influenced by the knowledge of another random variable:

$$
\begin{aligned}
\mu_{t} & =E\left[r_{t} \mid \Omega_{t-1}\right] \text { and } \\
h_{t} & =E\left[\left(r_{t}-\mu_{t}\right)^{2} \mid \Omega_{t-1}\right]
\end{aligned}
$$

with $\mu_{t}$ being the mean of $r_{t}$ given the information from the past period $t-1, \Omega_{t-1}$. This means that $R_{t}$ is generated by the following process:

$$
R_{t}=\mu_{t}+\sqrt{h_{t}} \varepsilon_{t},
$$

with:

$$
E\left[\varepsilon_{t} \mid \Omega_{t-1}\right]=0
$$

and

$$
\operatorname{Var}\left[\varepsilon_{t} \mid \Omega_{t-1}\right]=1
$$

$\operatorname{A~GARCH}(p, q)$ model assumes that the returns $R_{t}$ in the mean equation is composed of the conditional mean $\mu$ and the price innovation $\varepsilon_{t}:^{36}$

$$
R_{t}=\mu+\varepsilon_{t},
$$

with

$$
\varepsilon_{t} \mid \Omega_{t-1} \sim N\left(0, h_{t}\right)
$$

However, to account for the serial dependence structure in the hedge fund returns, which are often caused by infrequent trading, the mean equation is modelled by an ARMA process:

$$
R_{t}=\mu_{t}+\sum_{k=1}^{m} \phi_{k} r_{t-k}+\sum_{l=1}^{n} \theta_{l} \varepsilon_{t-l}+\varepsilon_{t}
$$

The conditional variance $h_{t}$ in a $\operatorname{GARCH}(p, q)$ model is defined as a function of the past squared error terms $\varepsilon_{t-j}^{2}$ and the conditional variance of 
past periods $h_{t-i} \cdot{ }^{37}$

$$
\begin{gathered}
h_{t}=\omega+\sum_{j=1}^{q} \alpha_{j} \varepsilon_{t-j}^{2}+\sum_{i=1}^{p} \beta_{i} h_{t-i}, \\
\text { with }: \varepsilon_{t}=R_{t}-\mu
\end{gathered}
$$

The parameters in equation (8) have to meet the following restrictions: $\omega>0, \alpha_{j}$, and $\beta_{i}>0$ for $i=1, \ldots, p$ and $j=1, \ldots, q$. The introduction of this non-negativity condition is necessary in order to exclude a negative variance. In addition, to provide stationarity the following condition must hold: $:^{38}$

$$
\sum_{j=1}^{q} \alpha_{j}+\sum_{i=1}^{p} \beta_{i}<1 .
$$

If the sum of $\alpha_{j}$ and $\beta_{i}$ have values close to one, the volatility is highly persistent, that is, volatility has a very long 'memory'. The condition of stationarity also includes the mean reverting property if the sum of the ARCH and GARCH term is significantly less than one. Thus, it appears that although the return volatility has quite a long memory, the volatility process nevertheless returns to its mean. One can test for mean reversion by comparing the average (stationary) unconditional mean of the $\operatorname{GARCH}(p, q)$ process with the sample estimate of the unconditional variance. The unconditional mean of the $\operatorname{GARCH}(p, q)$ process is calculated as the ratio between $\omega$ and $\left(1-\alpha_{j}-\beta_{i}\right)$.

Previous tests have shown that a lag structure of $p=1$ and $q=1$ is already sufficient to attain adequate estimation results. Thus, the choice of parameters in the empirical analyses in the next section are restricted to a $\operatorname{GARCH}(1,1)$ model. ${ }^{39}$ For estimating the parameter vector $\Theta=\left(\omega, \alpha_{j}, \beta_{i}\right)$, the maximum likelihood technique is applied under the assumption that the residuals $\varepsilon_{t}$ follow a conditional Gaussian (normal) distribution. ${ }^{40}$

\section{Asymmetric conditional volatility models}

As already mentioned, not only the magnitude but also the sign of an innovation can influence volatility. Hence, a relationship between the volatility of returns and the returns themselves is assumed, to have a negative sign, that is, decreasing asset returns lead to an increasing volatility and vice versa (Engle and $\mathrm{Ng}^{41}$ ).

In relevant literature, several approaches are used to model the leverage effect. There are the $\operatorname{QGARCH}(p, q)$, Quadratic GARCH and the $\operatorname{NGARCH}(p, q)$ model and the Non-linear Asymmetric GARCH, among other GARCH modifications (Sentana, ${ }^{42}$ Engle and $\mathrm{Ng}^{41}$ ). The $\operatorname{EGARCH}(p, q)$ model, developed by Nelson, ${ }^{43}$ assumes normally distributed residuals and can be expressed as:

$$
\begin{aligned}
\log \left(h_{t}\right)= & \omega+\sum_{i=1}^{p} \beta_{i} \log \left(h_{t-i}\right) \\
& +\sum_{j=1}^{q} \alpha_{j}\left(\left|\frac{\varepsilon_{t-j}}{\sqrt{h_{t-j}}}-\sqrt{\frac{2}{\pi}}\right|+\gamma_{j} \frac{\varepsilon_{t-j}}{\sqrt{h_{t-j}}}\right)
\end{aligned}
$$

Unlike the linear $\operatorname{GARCH}(p, q)$ model in equation (8), the conditional variance in the EGARCH model is formulated in logarithms. In doing so, all restrictions become irrelevant, particularly the non-negativity condition for the parameters of the conditional variance. ${ }^{44}$ On the one hand, the unconditional standard deviation is considered by the parameter $\alpha_{j}$, that includes the effects of price innovations $j$ periods in the past, and on the other by the term $\gamma_{j} \alpha_{j}$ that considers the effect of the sign. In a model comparison where a number of different ARCH, GARCH, EGARCH and other more complex semi-parametric and non-parametric models were compared, Pagan and Schwert ${ }^{45}$ 
could provide empirical evidence that a simple EGARCH $(1,1)$ model is already a sufficient parameterisation to adequately model the dynamics of price innovations. As a result of the modelling of volatility clustering, positive parameter values should result for $\alpha_{1}$ and, in order to take the leverage effect into account, negative values result for $\gamma_{1}$.

\section{GARCH-type VaR}

Although the CF expansion includes the deviations from a normal distribution, it ignores the volatility clustering of the returns. However, as $\mathrm{ARCH}$ effects establish the fact that one bad day with highly negative returns makes a consecutive bad day more likely than without ARCH effects, the unconditional standard deviation $\sigma$ is replaced by the estimated conditional standard deviation of the GARCH process:

$$
V a R_{t}=-\left(\eta \cdot \sqrt{h_{t}}-\mu_{t}\right)
$$

\section{EMPIRICAL ANALYSIS OF STOCHASTIC VOLATILITY}

\section{Data}

For the empirical analysis of the stochastic volatilities, daily data from the S\&P hedge fund index series (SPHG) are utilised, as this is the hedge fund database with the longest daily track record, starting in September 2002. However, the use of daily indices has several drawbacks. Firstly, all available daily hedge fund indices are based on managed account platforms. In their empirical analysis on hedge funds based on managed accounts, Haberfelner et al. ${ }^{46}$ show that the managed account composite with 0.37 exhibits a significant lower Sharpe ratio than the Eurekahedge composite (1.08). Moreover, investors obtain a premium of 8.19 per cent per annum for not going the managed account way. Thus, one can conclude that the SPHG benchmark for the hedge fund universe suffers from selection bias as managers of account platform have strict requirements in terms of transparency, liquidity and investability. Secondly, from the investor's perspective, 'traditional' hedge fund indices also suffer from survivorship, selection and self-selection biases. However, it is important to mention that these are non-investable hedge fund indices. Fung and $\mathrm{Hsieh}^{47}$ argue that fund of hedge fund data are less prone to these data biases than noninvestable hedge fund indices. Drawing on conclusions from Fung and $\mathrm{Hsieh}^{48}$, we are of the opinion that the investable hedge fund indices used in this study are good proxies for the advancement of diversified hedge fund portfolios.

\section{Descriptive statistics}

The observation period ranges from 30th September, 2002 until 31st May 2006. During this period, 926 return observations resulted, whereby the last month serves as an out-ofsample forecast period. By using daily data, a sufficiently large sample is available that makes the existence of ARCH effects, and the occurrence of volatility clustering, in particular, a requirement for estimating GARCH models.

Denoting $P_{t}$ as the price or the NAV of a particular hedge fund style at the time $t$, the continuous return for the period $t-1$ until $t$ is calculated as follows:

$$
r_{t}=\ln \left(\frac{P_{t}}{P_{t-1}}\right) \cdot 100
$$


Table 1 gives an overview of the return and risk characteristics of the various style indices denominated in US dollar. Thereby, the mean as well as the standard deviation are provided as annualised values. As can be seen, the performance of the particular strategies in the observed period is very heterogeneous and altogether not favourably compared to the other financial assets shown in the lower part of the table. For instance, the style event-driven has the highest annual return with 9.20 per cent, followed by the directional style with 7.01 per cent, while the style arbitrage (2.79 per cent) and the strategy managed futures (4.73 per cent) exhibit the lowest total returns. None of the hedge fund indices exceed the returns of the other financial assets with the exception of bonds. $^{49}$

In reference to the second moment, the hedge fund composite and the three style indices exhibit the lowest volatilities, whereas managed futures simultaneously display extraordinary variability and low annualised returns. However, using only volatility as a risk measurement can only be reasonable if it can be assumed that the observed returns are normally distributed.

According to the test statistics of the Jarque-Bera normality test, the null hypothesis of normally distributed returns can only be accepted for the index of small capitalised companies. In contrast, the evidence of leptokurtosis or positive excess kurtosis of hedge fund returns supports the

Table 1: Descriptive statistics, 09/30/2002-04/28/2006

\begin{tabular}{|c|c|c|c|c|c|c|}
\hline Asset & Indices & $\begin{array}{l}\text { Mean } \\
\bar{r}_{\text {ann. }}(\text { in } \%)\end{array}$ & $\begin{array}{l}\text { Volatility } \\
\bar{\sigma}_{a n n .}(\text { in } \%)\end{array}$ & Skewness & Kurtosis & $\begin{array}{l}\text { Jarque-Bera } \\
\text { test }\end{array}$ \\
\hline \multirow[t]{5}{*}{ Hedge fund strategies } & SPHG composite & 6.396 & 2.076 & -0.262 & 3.965 & $45.456^{\star \star}$ \\
\hline & SPHG arbitrage & 2.791 & 3.272 & 0.109 & 3.836 & $28.101^{\star \star \star}$ \\
\hline & SPHG event driven & 9.204 & 2.090 & 0.086 & 5.402 & $218.39^{\star \star \star}$ \\
\hline & SPHG directional & 7.013 & 4.767 & -0.242 & 4.097 & $54.146^{\star \star \star}$ \\
\hline & SPHG managed futures & 4.733 & 16.193 & -0.380 & 4.258 & $75.538^{\star \star \star}$ \\
\hline \multirow[t]{8}{*}{ Financial assets } & S\&P 500 & 14.906 & 14.207 & 0.332 & 5.284 & $213.10^{\star \star \star}$ \\
\hline & NASDAQ composite & 16.904 & 20.789 & 0.239 & 4.800 & $130.66^{\star \star \star}$ \\
\hline & Wilshire growth & 12.799 & 14.062 & 0.269 & 4.299 & $74.456^{\star \star \star}$ \\
\hline & Wilshire value & 19.092 & 14.946 & 0.236 & 5.785 & $300.59^{\star \star \star}$ \\
\hline & Wilshire small cap & 23.077 & 16.688 & -0.104 & 3.198 & $3.115^{\star}$ \\
\hline & Wilshire large cap & 15.405 & 13.941 & 0.312 & 5.178 & $193.43^{\star \star \star}$ \\
\hline & J.P. Morgan bond index & 2.030 & 4.810 & -0.276 & 4.550 & $105.384^{\star \star \star}$ \\
\hline & GS commodity index & 18.084 & 23.661 & 0.081 & 3.403 & $7.087^{\star \star}$ \\
\hline
\end{tabular}

Notes: Based on daily continuously compounded returns for 904 observations. ${ }^{\star \star \star, ~}{ }^{\star \star},{ }^{\star}$ for significance at 99,95 and $90 \%$ confidence levels (rejection of the normal distribution); managed futures contains 839 observations covering the period from $01 / 02 / 2003$ to $04 / 28 / 2006$. 
existence of ARCH effects in these time series. Most of the other financial assets are also leptokurtically distributed, which is a typical characteristic of daily equity returns.

Furthermore, the composite, directional and managed futures indices are negatively skewed.

As can be seen in Table 2, the returns of the various styles of the SPHG hedge fund indices do not show high autocorrelation coefficients, but some of them are still highly significant. As mentioned, the marking-to-market problem emerges in cases of positive autocorrelation, where the true standard deviation is underestimated.

In real estate literature, several desmoothing techniques exist in order to adjust data series from positive autocorrelation caused by infrequent trading. ${ }^{50}$ In this paper, autocorrelation is utilised to model the returngenerating process in the mean equation of the GARCH models. In addition, with first-order negative correlation coefficients as they appear for arbitrage and managed futures, the standard deviations of the unsmoothed time series would decrease. Table 3 shows the estimated ARMA processes for the composite, arbitrage and directional index. As event-driven and managed futures do not exhibit serial correlation, the mean equation simply consists of a constant term.

Finally, autocorrelation diagnostic tests for the residuals were computed to check the adequacy of the estimated ARMA models. In addition, the Ljung-Box test of squared residuals and the LM test control for ARCH effects exist only for the arbitrage and event-driven styles. In this context, notice that tests of volatility clustering are of low power, that is, they allow for type-II error. However, as mentioned earlier, the existence of fat tails permits the estimation of $\mathrm{ARCH} /$
GARCH models. Another test of ARCH effects to examine volatility clustering consists of the Ljung-Box test for squared returns, which is shown in Table 4 . With the exception of composite and managed futures, the strategies thus have dependencies in the squared returntime series. This suggests the existence of a timedependent conditional variance. To analyse the stochastic properties of those return-time series, a symmetric as well as an asymmetric volatility model is applied in the next section.

\section{Parameter estimation}

Since volatility clustering is a specific characteristic of speculative prices, the conditional second moment is modelled using a variation of the GARCH process originally suggested by Bollerslev ${ }^{37}$. By estimating these conditional volatility models for the particular hedge fund style indices, it is possible, in the second step, to check the consistency of certain properties of volatility that are again important for the forecasting of volatility.

The ARMA-GARCH results are given in Table 5. Approximate maximum likelihood estimates of the parameters in the model were obtained by using the Berndt et al. ${ }^{51}$ algorithm. Standard errors are computed using the robust method of Bollerslev-Wooldridge. The estimation results show that the $\hat{\alpha}$ coefficients are significant at the 5 per cent level with the exception of the directional style, that is, $\mathrm{ARCH}$ effects in the return-time series of the hedge funds exist. The parameter restrictions are fulfilled for all hedge fund indices; even though the volatility of returns has a long memory, the volatility processes are still mean-reverting ones. For the directional strategy and the managed futures index, the persistence of the volatility, 
Table 2: Autocorrelations

\begin{tabular}{lllllllll}
\hline Strategy indices & $\operatorname{Lag}(1)$ & $\operatorname{Lag}(2)$ & $\operatorname{Lag}(3)$ & $\operatorname{Lag}(4)$ & $\operatorname{Lag}(5)$ & $\operatorname{Lag}(10)$ & $\operatorname{Lag}(15)$ & $\operatorname{Lag}(20)$ \\
\hline SPHG composite & & & & & & & & \\
ACF & $0.071^{\star \star}$ & 0.049 & 0.041 & 0.034 & 0.051 & 0.018 & 0.024 & -0.030 \\
PACF & $0.071^{\star \star}$ & 0.044 & 0.035 & 0.027 & 0.044 & 0.015 & 0.002 & -0.050
\end{tabular}

SPHG arbitrage

$\begin{array}{lllrlrrrr}\text { ACF } & -0.189^{\star \star} & -0.107^{\star \star} & 0.010 & -0.001 & 0.046 & 0.026 & 0.047 & 0.020 \\ \text { PACF } & -0.189^{\star \star} & -0.148^{\star \star} & -0.044 & -0.025 & 0.039 & 0.026 & 0.065 & 0.020\end{array}$

SPHG event driven

$\begin{array}{lllllllll}\text { ACF } & 0.056 & 0.016 & 0.058 & 0.027 & 0.043 & 0.098 & 0.098^{\star \star} & 0.039 \\ \text { PACF } & 0.056 & 0.013 & 0.057 & 0.021 & 0.039 & 0.042 & 0.089^{\star \star} & 0.022\end{array}$

SPHG directional

$\begin{array}{lllllllll}\text { ACF } & 0.084^{\star \star} & -0.021 & -0.011 & 0.000 & -0.006 & -0.013 & -0.043 & -0.028 \\ \text { PACF } & 0.084^{\star \star} & -0.028 & -0.007 & 0.001 & -0.007 & -0.006 & -0.061^{\star \star} & -0.025\end{array}$

SPHG managed fut.

\begin{tabular}{lllllllll} 
ACF & -0.023 & -0.036 & -0.003 & 0.064 & -0.057 & 0.005 & -0.024 & -0.026 \\
PACF & -0.023 & -0.037 & -0.005 & 0.063 & -0.055 & -0.003 & -0.024 & -0.033 \\
\hline
\end{tabular}

measured as the sum of $\hat{\alpha}$ and $\hat{\beta}$, is much higher compared to the other hedge fund indices. An intuitive approach for measuring the persistence in volatility processes is the computation of the half-life period (HLP) of a shock on the process, that is, the length until half of the volatility, generated by a price innovation, is decomposed. The HLP, which is computed as $H L P=\log (0.5) /[\log (\hat{\alpha}+\hat{\beta})]$, takes 17 days for the composite index and 25 days for the event driven style, whereby the HLP of 47 and 51 days for managed futures and directional style index are much higher.

However, since the sum of the GARCH terms are still smaller than one, all strategies show a mean-reverting behaviour. The property of mean reversion exists if the unconditional variance from the $\operatorname{GARCH}(1,1)$ process is close to the estimated unconditional sample variance. The unconditional variance from the GARCH models is computed as the ratio of the constant $\hat{\omega}$ and the expression $(1-\hat{\alpha}-\hat{\beta})$. For instance, for the arbitrage style an unconditional variance of 0.0391 results which corresponds to an annualised volatility of $\bar{\sigma}_{a n n}=3.128$ per cent that is thus approximately the same as the estimated sample volatility (3.272) from Table 1. Taken together, all unconditional volatilities acquired from the GARCH processes are close to their sample estimators except for the managed futures index. The Ljung-Box test for testing on dependencies of the residuals $Q(5)$ 
Table 3: ARMA-modelling

\begin{tabular}{|c|c|c|c|c|c|}
\hline Indices & SPHG composite & SPHG arbitrage & SPHG event driven & SPHG directional & SPHG managed fut \\
\hline Model & ARMA $(1,1)$ & ARMA $(1,2)$ & - & ARMA $(1,2)$ & - \\
\hline \multirow[t]{2}{*}{$\hat{\mu}$} & $0.028^{\star \star \star}$ & $0.012^{\star \star}$ & $0.037^{\star \star \star}$ & $0.030^{\star \star \star}$ & 0.019 \\
\hline & $(0.007)$ & $(0.005)$ & $(0.004)$ & $(0.010)$ & $(0.035)$ \\
\hline \multirow[t]{2}{*}{$\hat{\phi}_{1}$} & $0.947^{\star \star \star}$ & $-0.222^{\star \star \star}$ & - & $0.879^{\star \star \star}$ & - \\
\hline & $(0.034)$ & $(0.033)$ & & $(0.153)$ & \\
\hline \multirow[t]{2}{*}{$\hat{\theta}_{1}$} & $-0.913^{\star \star \star}$ & - & - & $-0.794^{\star \star \star}$ & - \\
\hline & $(0.044)$ & & & $(0.156)$ & \\
\hline \multirow[t]{2}{*}{$\hat{\theta}_{2}$} & - & $-0.155^{\star \star \star}$ & - & $-0.082^{\star \star}$ & - \\
\hline & & $(0.034)$ & & $(0.035)$ & \\
\hline AIC & -1.233 & -0.378 & - & 0.438 & - \\
\hline SIC & -1.217 & -0.359 & - & 0.460 & - \\
\hline$Q(5)$ & 0.598 & 3.269 & 8.480 & 0.270 & 7.828 \\
\hline$Q^{2}(5)$ & 4.803 & $46.940^{\star \star \star}$ & $14.278^{\star \star}$ & 4.080 & 1.241 \\
\hline LM-test & 1.068 & $9.461^{\star \star \star}$ & $3.393^{\star}$ & 2.161 & 0.033 \\
\hline
\end{tabular}

Notes: Based on daily continuously compounded returns for 904 observations; managed futures 839 observations $01 / 02 / 2003$ to $04 / 28 / 2006$; standard errors are presented in parenthesis; ${ }^{\star \star \star, \star \star, \star}$ for significance at $99 \%, 95 \%$ and $90 \%$ confidence levels; $\mathrm{Q}(5)$ and $\mathrm{Q}^{2}(5)$ are the Ljung-Box statistics for residuals and squared residuals at lag five.

Table 4: Test for ARCH effects - squared returns

\begin{tabular}{lllllllllll}
\hline Indices & $\hat{\rho}_{1}$ & \multicolumn{1}{c}{$\hat{\rho}_{2}$} & $\hat{\rho}_{3}$ & \multicolumn{1}{l}{$\hat{\rho}_{4}$} & $\hat{\rho}_{5}$ & $\hat{\rho}_{10}$ & $\hat{\rho}_{15}$ & $L B(5)$ & $L B(10)$ & $L B(15)$ \\
\hline SPHG composite & 0.007 & 0.039 & 0.007 & -0.010 & 0.030 & 0.038 & 0.042 & 2.371 & 7.692 & 19.255 \\
SPHG arbitrage & 0.174 & 0.077 & 0.072 & 0.067 & 0.157 & 0.113 & 0.100 & $64.22^{\star \star \star}$ & $93.61^{\star \star \star}$ & $108.9^{\star \star \star}$ \\
SPHG event-driven & 0.045 & 0.080 & 0.009 & 0.050 & 0.007 & 0.019 & 0.045 & $10.09^{\star}$ & $20.80^{\star \star}$ & $23.62^{\star \star}$ \\
SPHG directional & 0.046 & -0.017 & 0.049 & 0.010 & 0.001 & 0.034 & 0.049 & 4.509 & $16.55^{\star}$ & $31.74^{\star \star \star}$ \\
SPHG managed fut. & 0.004 & 0.003 & 0.029 & 0.026 & 0.007 & 0.030 & 0.006 & 1.331 & 3.845 & 11.72 \\
\hline
\end{tabular}

Notes: ${ }^{\star \star \star, ~}{ }^{\star \star},{ }^{\star}$ for significance of Ljung-Box statistics at 99,95 and $90 \%$ confidence level of squared daily returns; LB denotes the Ljung-Box test statistics at lag 5, 10 and 15, respectively.

and squared residuals $Q^{2}(5)$ as well as the ARCH-LM(1) test, confirm that no linear or non-linear dependencies exist, and that the models take the heteroscedasticity and the changing unconditional and conditional variance in the return-time series into account. Finally, the Jarque-Bera statistic suggests that skewness and kurtosis in the standardised 
Table 5: ARMA-GARCH $(p, q)$ model for hedge fund indices

\begin{tabular}{|c|c|c|c|c|c|}
\hline Parameter & $\begin{array}{l}\text { SPHG } \\
\text { composite }\end{array}$ & $\begin{array}{l}\text { SPHG } \\
\text { arbitrage }\end{array}$ & $\begin{array}{l}\text { SPHG } \\
\text { event-driven }\end{array}$ & $\begin{array}{l}\text { SPHG } \\
\text { directional }\end{array}$ & $\begin{array}{l}\mathrm{SPHG}_{2} \text { managed } \\
\mathrm{fut}_{3} .\end{array}$ \\
\hline \multicolumn{6}{|l|}{ Mean equation } \\
\hline \multirow[t]{2}{*}{$\hat{c}$} & $0.030^{\star \star \star}$ & $0.009^{\star \star}$ & $0.038^{\star \star \star}$ & $0.032^{\star \star \star}$ & $0.023^{\star \star}$ \\
\hline & (0.008) & (0.004) & $(0.004)$ & $(0.011)$ & $(0.009)$ \\
\hline \multirow[t]{2}{*}{$\hat{\phi}_{1}$} & $0.951^{\star \star \star}$ & $-0.180^{\star \star \star}$ & - & $0.901^{\star \star \star}$ & - \\
\hline & $(0.026)$ & $(0.035)$ & & $(0.076)$ & \\
\hline \multirow[t]{2}{*}{$\hat{\theta}_{1}$} & $-0.911^{\star \star \star}$ & - & - & $-0.835^{\star \star \star}$ & - \\
\hline & $(0.035)$ & & & $(0.086)$ & \\
\hline \multirow[t]{2}{*}{$\hat{\theta}_{2}$} & - & $-0.168^{\star \star \star}$ & - & $-0.060^{\star}$ & - \\
\hline & & $(0.037)$ & & $(0.035)$ & \\
\hline \multicolumn{6}{|l|}{ Variance equation } \\
\hline \multirow[t]{2}{*}{$\hat{\omega}$} & 0.001 & 0.001 & 0.0001 & $0.001^{\star \star \star}$ & $0.001^{\star}$ \\
\hline & (0.001) & $(0.001)$ & $(0.000)$ & $(0.001)$ & $(0.001)$ \\
\hline \multirow[t]{2}{*}{$\hat{\alpha}$} & $0.040^{\star \star}$ & $0.057^{\star \star \star}$ & $0.043^{\star \star}$ & $0.019^{\star}$ & $0.023^{\star \star}$ \\
\hline & $(0.016)$ & (0.018) & $(0.019)$ & $(0.010)$ & $(0.011)$ \\
\hline \multirow[t]{2}{*}{$\hat{\beta}$} & $0.920^{\star \star \star}$ & $0.918^{\star \star \star}$ & $0.929^{\star \star \star}$ & $0.968^{\star \star \star}$ & $0.963^{\star \star \star}$ \\
\hline & (0.039) & $(0.029)$ & $(0.035)$ & $(0.012)$ & $(0.016)$ \\
\hline AIC & -1.247 & -0.433 & -1.237 & 0.409 & 0.418 \\
\hline SIC & -1.215 & -0.401 & -1.215 & 0.446 & 0.439 \\
\hline $\log \mathrm{L}$ & 568.94 & 201.41 & 562.88 & -177.50 & -184.89 \\
\hline$Q(5)$ & 0.518 & 4.174 & $11.276^{\star \star}$ & 0.427 & 4.844 \\
\hline$Q^{2}(5)$ & 1.486 & 1.146 & 2.974 & 2.182 & 2.507 \\
\hline ARCH-LM test & 0.000 & 0.001 & 0.023 & 0.273 & 0.210 \\
\hline J.B. & $39.691^{\star \star \star}$ & $12.808^{\star \star \star}$ & $188.41^{\star \star \star}$ & $23.065^{\star \star \star}$ & $27.333^{\star \star \star}$ \\
\hline$\hat{\alpha}+\hat{\beta}$ & 0.960 & 0.975 & 0.973 & 0.987 & 0.985 \\
\hline HLP & 17.151 & 27.618 & 25.163 & 51.368 & 47.370 \\
\hline $\bar{\sigma}_{a n n .}($ in $\%)$ & 2.08 & 3.13 & 2.12 & 4.92 & 4.91 \\
\hline
\end{tabular}

Notes: Based on daily continuously compounded returns for the time period 09/30/2002 to 04/28/2006 (904 observations); ${ }^{\star \star \star},{ }^{\star \star}$ and ${ }^{\star}$ for the significance of the GARCH coefficients at the 99,95 and $90 \%$ confidence level; Bollerslev-Wooldridge robust standard errors are presented in parenthesis.

residuals are reduced but not completely eliminated.

Through assessment of an ARMAEGARCH(1,1) model, an examination of asymmetric effects on the conditional variance is conducted. The coefficient $\hat{\gamma}$ from Table 6 shows that for the arbitrage and event-driven management styles the sign of a price innovation 
Table 6: ARMA-EGARCH(p,q) model for hedge fund indices

\begin{tabular}{|c|c|c|c|c|c|}
\hline Parameter & $\begin{array}{l}\text { SPHG } \\
\text { composite }\end{array}$ & $\begin{array}{l}\text { SPHG } \\
\text { arbitrage }\end{array}$ & $\begin{array}{l}\text { SPHG } \\
\text { event-driven }\end{array}$ & $\begin{array}{l}\text { SPHG } \\
\text { directional }\end{array}$ & $\begin{array}{l}\text { SPHG } \\
\text { managed fut }{ }_{2} .\end{array}$ \\
\hline \multicolumn{6}{|l|}{ Mean equation } \\
\hline \multirow[t]{2}{*}{$\hat{c}$} & $0.031^{\star \star}$ & $0.008^{\star}$ & $0.038^{\star \star \star}$ & $0.034^{\star \star}$ & $0.032^{\star \star \star}$ \\
\hline & $(0.013)$ & $(0.004)$ & $(0.004)$ & $(0.013)$ & $(0.010)$ \\
\hline \multirow[t]{2}{*}{$\hat{\phi}_{1}$} & $0.976^{\star \star \star}$ & $-0.187^{\star \star \star}$ & - & $0.947^{\star \star \star}$ & - \\
\hline & $(0.015)$ & $(0.035)$ & & $(0.044)$ & \\
\hline \multirow[t]{2}{*}{$\hat{\theta}_{1}$} & $-0.934^{\star \star \star}$ & - & - & $-0.873^{\star \star \star}$ & - \\
\hline & $(0.021)$ & & & $(0.056)$ & \\
\hline \multirow[t]{2}{*}{$\hat{\theta}_{2}$} & - & $-0.156^{\star \star \star}$ & - & $-0.062^{\star}$ & - \\
\hline & & $(0.037)$ & & $(0.035)$ & \\
\hline \multicolumn{6}{|l|}{ Variance equation } \\
\hline \multirow[t]{2}{*}{$\hat{\omega}$} & $-0.797^{\star \star \star}$ & $-0.204^{\star \star \star}$ & $-0.631^{\star \star}$ & $-1.366^{\star \star \star}$ & $-1.647^{\star \star \star}$ \\
\hline & $(0.271)$ & $(0.077)$ & $(0.294)$ & $(0.415)$ & $(0.538)$ \\
\hline \multirow[t]{2}{*}{$\hat{\alpha}$} & $0.142^{\star \star \star}$ & $0.134^{\star \star \star}$ & $0.171^{\star \star \star}$ & $0.140^{\star}$ & $0.131^{\star}$ \\
\hline & $(0.052)$ & $(0.040)$ & $(0.060)$ & $(0.074)$ & $(0.078)$ \\
\hline \multirow[t]{2}{*}{$\hat{\gamma}$} & $-0.110^{\star \star \star}$ & -0.009 & -0.058 & $-0.172^{\star \star \star}$ & $-0.175^{\star \star \star}$ \\
\hline & $(0.038)$ & $(0.022)$ & $(0.040)$ & $(0.055)$ & $(0.056)$ \\
\hline \multirow[t]{2}{*}{$\hat{\beta}$} & $0.833^{\star \star \star}$ & $0.970^{\star \star \star}$ & $0.876^{\star \star \star}$ & $0.483^{\star \star \star}$ & $0.362^{\star}$ \\
\hline & $(0.061)$ & $(0.017)$ & $(0.065)$ & $(0.165)$ & $(0.217)$ \\
\hline AIC & -1.255 & -0.434 & -1.241 & 0.423 & 0.426 \\
\hline SIC & -1.218 & -0.397 & -1.214 & 0.465 & 0.452 \\
\hline $\log L$ & 573.71 & 203.15 & 565.84 & -182.80 & -187.46 \\
\hline$Q(5)$ & 0.502 & 4.314 & 8.832 & 1.471 & 5.313 \\
\hline$Q^{2}(5)$ & 1.112 & 0.833 & 3.363 & 2.761 & 3.393 \\
\hline ARCH-LM test & 0.082 & 0.009 & 0.158 & 0.001 & 0.008 \\
\hline J.B. & $20.441^{\star \star \star}$ & $11.439^{\star \star \star}$ & $179.70^{\star \star \star}$ & $24.586^{\star \star \star}$ & $24.775^{\star \star \star}$ \\
\hline
\end{tabular}

Notes: Based on daily continuously compounded returns for the time period 09/30/2002 to 04/28/2006 (904 observations); ${ }^{\star \star \star},{ }^{\star \star}$ and ${ }^{\star}$ for the significance of the EGARCH coefficients at the 99,95 and $90 \%$ confidence levels; Bollerslev-Wooldridge robust standard errors are presented in parenthesis.

has no influence on the conditional variance, whereas for the composite, directional and managed futures index the coefficients for the negative standardised residuals in $t$ increases the volatility at time $t+1$. Comparing these results with the descriptive statistic from Table 1, one can easily see that asymmetric effects on conditional volatility are absent mainly in those 

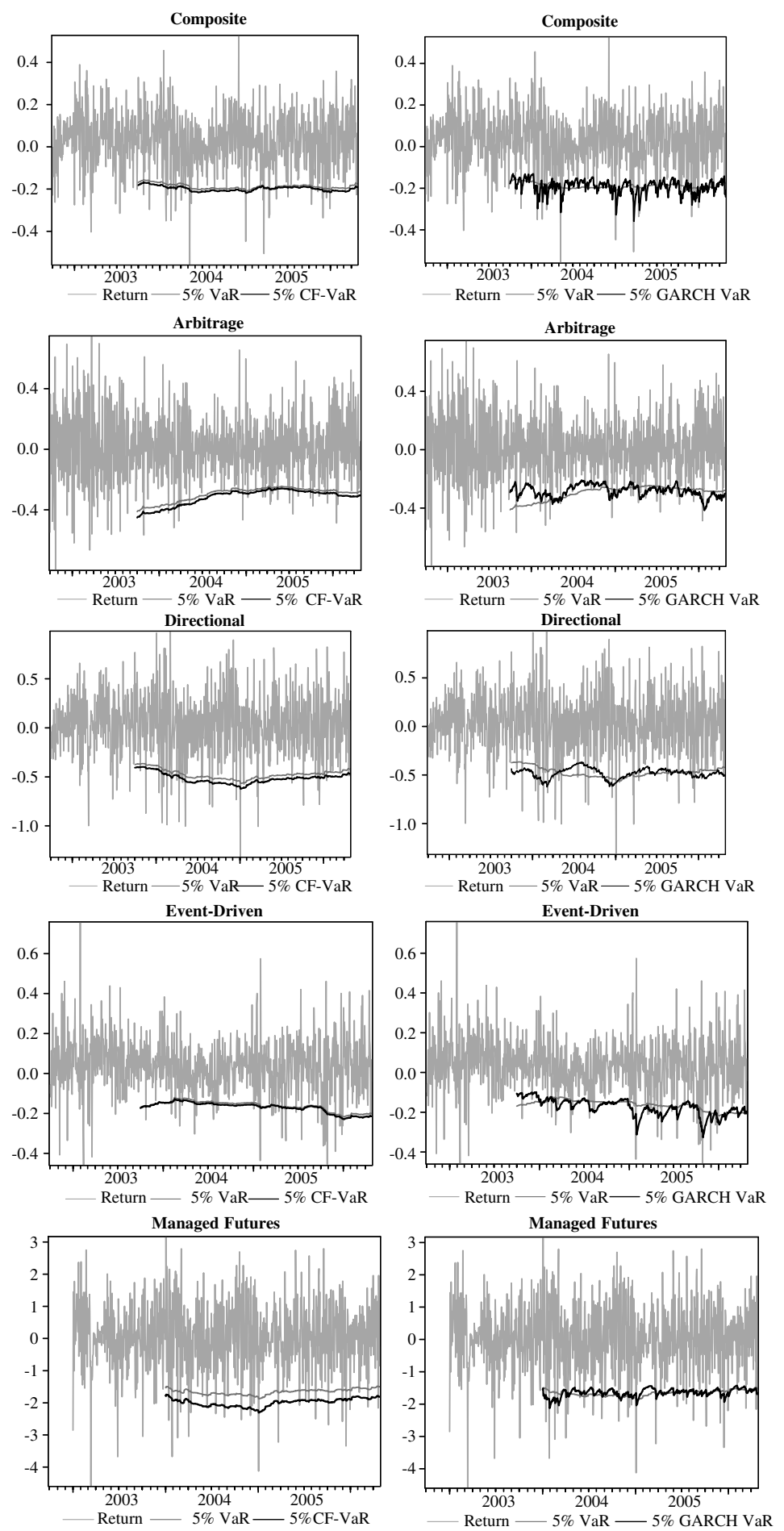

Figure 2: Comparison of the different VaR estimations

Notes: The continuously compounded returns start on 10/02/2002, whereas the VaR needs a prior observation period of one year and starts on 10/01/2003. Accordingly, for managed futures, the return series starts on 01/02/2003 and the VaR on 02/01/2004 
style indices that do not have (significant) negative skewness coefficients.

A comparison between the estimates of conventional and CF-VaR for the five hedge fund indices is shown in Figure 2. The underestimation can be seen most clearly for directional and managed futures where negative skewness and excess kurtosis reach relatively high values. In addition, the estimations of GARCH-type VaR can trace the return process much better than the conventional VaR. Furthermore, it suggests that the actual risk compared to the VaR, under the normality assumption, is much higher in down-market phases, as can be seen from the event-driven style at the end of 2005. In contrast, during tranquil periods the normal VaR overestimates the actual risk position as can be seen from the arbitrage style for the year 2004. Thus, the conventional and CF-VaR are quite static, whereas the GARCH-type $\mathrm{VaR}$ is more sensitive to changes in the return process.

\section{Conditional variance forecasts}

The parameters of the estimated GARCH models, as well as the observations of the squared residuals and the conditional variance, can be used to compute variance forecasts of the hedge fund style returns. Using 28th April, 2006 as the last sample observation, a recursive daily out-ofsample forecast for the next six days is computed. For a $\operatorname{GARCH}(1,1)$ model, the forecast for the period $T+1$ is $h_{T+1}=\hat{\omega}+\hat{\alpha} \varepsilon_{T}^{2}+\hat{\beta} h_{T}$ with $\varepsilon_{T}^{2}$ and $h_{T}$ being the last observation of the squared returns and the conditional variance at the end of the sample period. For the forecasts from $T+2$ to $T+6$, the expected values of the squared residuals and the conditional variance have to be computed according to the following equation:

$$
h_{T+2}=\hat{\omega}+\hat{\alpha} E_{T}\left[\varepsilon_{T+1}^{2}\right]+\hat{\beta} E_{T}\left[h_{T+1}\right]
$$

which is denoted for the general case $T+x$ as $h_{T+x}=\hat{\omega}+(\hat{\alpha}+\hat{\beta}) h_{T+x-1}$. Thus, only the estimated parameters and the conditional variance of the last forecast period are used for the forecast of the next period. The forecast of the conditional variance of the EGARCH models for the period $T+1$ is calculated as:

$$
h_{T+1}=\exp (\hat{\omega}) \cdot \hat{h}_{T}^{\hat{\beta}} \cdot \exp \left(\hat{\alpha}\left|\frac{\varepsilon_{T}}{\sqrt{h_{T}}}\right|+\hat{\gamma} \frac{\varepsilon_{T}}{\sqrt{h_{T}}}\right)
$$

While the general form for $T+x$ with $x>1$ is described by:

$$
\begin{aligned}
h_{T+x}= & \exp (\hat{\omega}) \cdot h_{T+x-1}^{\hat{\beta}} \\
& \times\left[\exp \left(\frac{(\hat{\gamma}+\hat{\alpha})^{2}}{2}\right) \Phi(\hat{\gamma}+\hat{\alpha})\right. \\
& \left.+\exp \left(\frac{(\hat{\gamma}-\hat{\alpha})}{2}\right) \Phi(\hat{\alpha}-\hat{\gamma})\right]
\end{aligned}
$$

with $\Phi(\hat{\gamma}+\hat{\alpha})$ and $\Phi(\hat{\alpha}-\hat{\gamma})$ as the values of the distribution function of the standard normal distribution. The forecasts for arbitrage, eventdriven and managed futures using a $\operatorname{GARCH}(1,1)$ model and for composite and directional using an EGARCH $(1,1)$ model are shown in Table 7 . In order to judge the quality of the forecasts, the Theil inequality coefficient (TIC) is also shown.

Depending on the value of the conditional variance at the end of the observation date the conditional variance increases or decreases slowly to its unconditional value because of the high $(\alpha+\beta)$ values which are close to one, and because shocks are unexpected and therefore not included in the forecast equation. In this context, only the arbitrage style overestimates the volatility of the next six days, whereas for the other indices, conditional volatility is underestimated in 
Table 7: Conditional volatility forecasts

\begin{tabular}{lccccccc}
\hline & $T+1(\%)$ & $T+2(\%)$ & $T+3(\%)$ & $T+4(\%)$ & $T+5(\%)$ & $T+6(\%)$ & TIC \\
\hline SPHG composite & 2.399 & 2.350 & 2.309 & 2.277 & 2.249 & 2.227 & 0.8315 \\
SPHG arbitrage & 3.025 & 3.027 & 3.030 & 3.032 & 3.035 & 3.037 & 0.9274 \\
SPHG event-driven & 2.181 & 2.179 & 2.178 & 2.176 & 2.175 & 2.174 & 0.6924 \\
SPHG directional & 4.800 & 4.841 & 4.819 & 4.808 & 4.803 & 4.800 & 0.8979 \\
SPHG managed futures & 16.46 & 16.43 & 16.41 & 16.38 & 16.36 & 16.34 & 0.9844 \\
\hline
\end{tabular}

Notes: For a comparison to the unconditional volatility of Table 1, the forecast values are represented as annualised conditional volatility; TIC denotes the Theil's inequality coefficient.

comparison to the unconditional annualised standard deviation. For instance, the forecast volatility of the composite index for the next day is 2.399 per cent, which is almost lower than the estimated sample volatility of 2.076 per cent in Table 1.

Furthermore, the values of the TIC suggest that the forecasts for the event-driven and the composite indices can be considered clearly superior to the random walk, whereas the forecasts for arbitrage, managed futures and directional indices are quite close to what a random walk would predict.

\section{Comparison of VaR forecasts}

The forecasted conditional variance of the $\operatorname{GARCH}(1,1)$ and $\operatorname{EGARCH}(1,1)$ models can be implemented in the VaR equation in order to obtain forecasts for the GARCH-type VaR. This requires that the standard deviation $\sigma_{t}$ from equation (2) be replaced by the square root of the forecasted conditional GARCH-Variance $h_{t}$ from equations (7) and (9): $V_{a} R_{T+x}=-\eta$.

$\sqrt{\hat{h}_{T+x}}-\hat{\mu}_{T+x}$ For the conditional variance $h_{t}$, a one month out-of-sample forecast from 28 th April, 2006 to 31st May, 2006 containing 23 observations is computed. Furthermore, the return process for the five indices are modelled and forecasted using an ARIMA process. The one-step ahead forecast can be calculated as:

$$
\hat{r}_{T+1}=\hat{\phi}_{0}+\sum_{k=1}^{m} \hat{\phi}_{k} r_{T+1-k}+\sum_{l=1}^{n} \hat{\theta}_{l} \varepsilon_{T+1-l}
$$

with $\hat{\phi}_{0}$ as a constant and $\hat{\phi}_{k}$ and $\hat{\theta}_{l}$ as the estimated AR and MA parameters of order $m$ and $n$, respectively. From the forecasted returns a mean $\hat{\mu}_{t}$ and, in the case of the normal VaR, a standard deviation $\hat{\sigma}_{t}$, as well as the skewness and the excess kurtosis in the case of the CF-VaR, can be obtained. Thus, the observation period of one year can move ahead one month to now include the forecasted month. In Table 8, the three different sample VaRs for the five indices are compared with their forecasts. To evaluate the performance of the forecasts, the Theil inequality coefficient (TIC), as well as the heteroscedasticity adjusted mean absolute error (HMAE) and heteroscedasticity adjusted root mean squared error (HRMSE), are applied. A relatively volatile period is chosen for the forecast month in order to observe how the forecasts match the actual changes in the VaR. Nevertheless, the VaR and the CF-VaR change 
only marginally over this period, which might explain the lower TIC values, particularly for composite, arbitrage and managed futures index. Forecasting a time series, which is more or less stable over time, results inevitably in adequate forecast performance when evaluated by TIC, HMAE and HRMSE. For the GARCH-type VaR, the performance ratios are much higher, especially for the very volatile composite index, and the directional and event-driven styles. This can be traced back to the time-varying property of the GARCH-type VaR models that display the return process much better in comparison with the other alternative VaR approaches.
However, Table 8 only exhibits the forecast performances and cannot show which of the three $\mathrm{VaR}$ types can actually match the timevarying risk adequately. To answer this question, the number of hits, that is, the number of times the returns fall below the actual VaR, would have to be compared with the forecasted 5 per cent VaR. However, the size of the forecast period (23 observations) is clearly too short if a hit is to be expected 5 per cent of the time. In addition, taking into account that ARIMA and GARCH models can only be used for shortterm forecasts, no reliable forecast period with the necessary number of observations can be

Table 8: One-month value at risk forecasts

\begin{tabular}{|c|c|c|c|c|c|c|c|c|c|}
\hline \multirow[t]{2}{*}{ Indices } & \multicolumn{3}{|l|}{ TIC } & \multicolumn{3}{|l|}{$H M A E$} & \multicolumn{3}{|c|}{ HRMSE } \\
\hline & $\operatorname{VaR}$ & $C F-V a R$ & $\begin{array}{l}\text { GARCH- } \\
\text { type VaR }\end{array}$ & $\operatorname{VaR}$ & $C F-V a R$ & $\begin{array}{l}\text { GARCH- } \\
\text { type VaR }\end{array}$ & $\operatorname{VaR}$ & $C F-V a R$ & $\begin{array}{l}\text { GARCH- } \\
\text { type VaR }\end{array}$ \\
\hline SPHG composite & 0.0152 & 0.0382 & 0.1532 & 0.0797 & 0.0657 & 0.2859 & 0.0085 & 0.0065 & 0.1342 \\
\hline SPHG arbitrage & 0.0206 & 0.0196 & 0.0478 & 0.0403 & 0.0380 & 0.0728 & 0.0424 & 0.0404 & 0.0975 \\
\hline SPHG event-driven & 0.0236 & 0.0236 & 0.1093 & 0.0360 & 0.0387 & 0.1236 & 0.0496 & 0.0498 & 0.2350 \\
\hline SPHG directional & 0.0429 & 0.0433 & 0.1228 & 0.0699 & 0.0719 & 0.2722 & 0.0899 & 0.0910 & 0.2809 \\
\hline SPHG managed futures & 0.0262 & 0.0296 & 0.0485 & 0.0393 & 0.0459 & 0.0782 & 0.0539 & 0.0611 & 0.0101 \\
\hline
\end{tabular}

Notes: The Theil's inequality coefficient (TIC) is normalised between 0 and 1 , where lower values indicate better forecast performances. The TIC is defined as:

$$
T I C=\frac{\sqrt{\frac{1}{n} \sum_{i=1}^{n}\left(\text { sample } V a R_{i}-\text { forecasted } V a R_{i}\right)^{2}}}{\sqrt{\frac{1}{n} \sum_{i=1}^{n}\left(\text { sample } V a R_{i}\right)^{2}}+\sqrt{\frac{1}{n} \sum_{i=1}^{n}\left(\text { forecasted } V a R_{i}\right)^{2}}}
$$

The heteroscedasticity adjusted MAE and RMSE are computed as:

$$
H M A E=\frac{1}{n} \sum_{i=1}^{n}\left|1-\frac{\text { sample } V a R_{i}}{\text { forecasted } V a R_{i}}\right|
$$

and

$$
\text { HRMSE }=\sqrt{\frac{1}{n} \sum_{i=1}^{n}\left(1-\frac{\text { sample } V a R_{i}}{\text { forecasted } V a R_{i}}\right)^{2}},
$$

respectively. 
made. However, one could ask which of the three VaR types generally model the timevarying risk adequately over the whole insample period (1st October 2003 to 28th April 2006). From the investor's point of view, the adequate VaR model should indicate how the positions of the hedge fund portfolio should be sized for the best protection against downside risk. This means that investors who include hedge funds in their asset allocation weigh portfolio positions with a low VaR, relative to the VaR of the whole portfolio, more heavily than those with a higher $\mathrm{VaR}$. For this reason the first term of equation (17) does include not only the numbers of hits, $\tilde{n}$, but also their value that is measured by the magnitude of the hit. The more the VaR is exceeded by the hit value, the stronger are the deviations weighted in the adjusted hit ratio. In addition, these squared deviations are weighted by the average value of the $\mathrm{VaR}$ position described by the second term:

$$
\begin{aligned}
\operatorname{HIT}_{\text {adj. }}= & \frac{1}{n} \sum_{i=1}^{\tilde{n}}\left(\text { HIT value }_{i}-V_{a R_{i}}\right)^{2} \\
& \times\left|\frac{1}{n} \sum_{i=1}^{n} V_{a}\right| \quad \forall V a R_{i}<0
\end{aligned}
$$

with $n$ as the number of total observations. A lower adjusted hit ratio indicates a better VaR.
As can be seen in Table 9, the GARCH-type VaR outperforms the other two VaRs in the case of composite, event-driven and directional strategies. For event driven strategy, one can see the GARCH-type VaR's ability to follow the return process much better than the other two VaRs, which then leaves the investor better prepared in case of a hit. Furthermore, an investor using the GARCH-type VaR is often warned prior to very negative returns due to a sharp increase in the VaR, whereas the other two VaRs do not show strong reactions. At the same time, the GARCH-type VaR decreases quickly after high volatility periods as can be seen for event-driven and directional strategies. Indeed, as in the case of arbitrage and managed futures strategies, where the GARCH-type VaR is dominated by the other two VaRs, the GARCH-type VaR sometimes tends to be too 'optimistic', decreasing too soon and so leading to hits that do not occur for the other two VaRs. Although the forecast performance for the GARCH-type VaR is not as accurate as that of the other VaRs, it dominates the other two VaRs in terms of the adjusted hit ratio.

\section{CONCLUSIONS}

In this paper, alternative volatility models such as $\operatorname{GARCH}(p, q)$ and $\operatorname{EGARCH}(p, q)$ for particular

Table 9: Adjusted Hit ratios of the alternative value at risk approaches

\begin{tabular}{lccc}
\hline$\times 10^{-3}$ & VaR & CF-VaR & GARCH-type VaR \\
\hline SPHG Composite & 0.1447 & 0.1337 & $\mathbf{0 . 1 1 3 4}$ \\
SPHG Arbitrage & 0.1269 & $\mathbf{0 . 0 9 5 8}$ & 0.1491 \\
SPHG Event-driven & 0.1216 & 0.1142 & $\mathbf{0 . 0 9 4 5}$ \\
SPHG Directional & 2.5586 & 2.2395 & $\mathbf{2 . 1 8 1 5}$ \\
SPHG Managed futures & 85.992 & $\mathbf{5 8 . 9 6 0}$ & 86.824 \\
\hline
\end{tabular}


hedge fund strategies were estimated and compared with each other. The examination of the conditional volatility of hedge fund strategy returns shows important differences concerning persistence, mean reversion and asymmetric effects among the strategies considered. The knowledge of the conditional volatility of hedge fund returns can be used to enhance the VaR estimation and forecast. While the normal VaR is generally based on the assumption of normally distributed returns, the CF expansion tends to result in a systematic downward shift in the VaR estimates. Furthermore, both VaR measurements are very inertial, meaning that they do not react immediately to small or large price changes. In contrast, the GARCH-type $\mathrm{VaR}$ is able to trace the return process. However, skewness and kurtosis are not completely eliminated by the GARCH modelling and, thus, some bias remains in the VaR estimations and forecasts. Performance ratios indicate an inferior forecast ability compared to the normal and $\mathrm{CF}-\mathrm{VaR}$. This is due to the fact that the GARCH-type VaR is more sensitive to changes in the return process. However, by introducing an adjusted hit ratio, one can demonstrate that the GARCH-type VaR adjusts much better to the time-varying risk. Hence, by allowing such a temporal risk control, GARCH-type VaR offers an enhanced protection against downside risk in a portfolio including hedge funds.

\section{References}

1 Hendricks, D. (1995) 'Evaluation of Value at Risk Models Using Historical Data', Working Paper, Federal Reserve Bank of New York.

2 Beder, T. S. (1995) 'VAR: Seductive but Dangerous', Financial Analysts Journal, Vol. 51, No. 5, pp. 12-24.

3 Marshall, C. and Siegel, M. (1996) 'Value at Risk: Implementing a Risk Measurement Standard', Working
Paper, The Wharton School, University of

Pennsylvania.

4 Fung, W. and Hsieh, D. (1997) 'Empirical Characteristics of Dynamic Trading Strategies: The Case of Hedge Funds', Review of Financial Studies, Vol. 10, No. 2, pp. 275-305.

5 Liang, B. (1999) 'On the Performance of Hedge Funds', Financial Analysts Journal, Vol. 55, No. 4, pp. $72-85$

6 Favre, L. and Galeano, J. (2002) 'Mean-modified Value-at-Risk Optimization with Hedge Funds', The Journal of Alternative Investments, Vol. 5, No. 2, pp. 21-25.

7 Further methods to calculate VaR for non-normally distributed variables include the partial Monte-Carlo, the Fourier method, and the Johnson transformation. As empirically shown by Mina and Ulmer (1999) the CF expansion is the most quickly calculated and intuitively traceable method. However, according to the distribution function the CF expansion is not always accurate. Mina, J. and Ulmer, A. (1999) 'DeltaGamma FourWays', Working Paper, Risk Metrics Group, LLC.

8 Agarwal, V. and Naik, N. Y. (2004) 'Risks and Portfolio Decisions Involving Hedge Funds', Review of Financial Studies, Vol. 17, No. 1, pp. 63-98.

9 In order to capture the fat-tailed and asymmetric returns, $\mathrm{Li}$ (1999) proposes to estimate VaR based on the moments volatility, skewness and kurtosis. Li, D. (1999) 'Value at Risk based on the Volatility, Skewness and Kurtosis', Working Paper, Riskmetrics Group.

10 Kellezi, E. and Gilli, M. (2000) 'Extreme Value Theory for Tail-Related Risk Measures', Working Paper, University of Geneva, Geneva.

11 Danielsson, J. and de Vries, C. G. (1998) 'Beyond the Sample: Extreme Quantile and Probability Estimation', Discussion Paper 298, London School of Economics.

12 Engle, R. F. and Patton, A. (2001) 'What Good is a Volatility Model?' Quantitative Finance, Vol. 1, No. 2, pp. 237-245.

13 Kat, H. M. and Lu, S. (2002) 'An Excursion Into the Statistical Properties of Hedge Fund Returns', Working Paper, The University of Reading.

14 Purcell, D. and Crowley, P. (1999) 'The Reality of Hedge Funds', Journal of Investing, Vol. 8, No. 3, pp. 26-44.

15 Agarwal, V. and Naik, N. Y. (2000) 'Multi-period Performance Persistence Analysis of Hedge Funds', Journal of Financial and Quantitative Analysis, Vol. 35, No. 3, pp. 327-342.

16 Ineichen, A. M. (2003) 'Absolute Returns - The Risk and Opportunities of Hedge Fund Investing', John Wiley \& Sons, London. 
17 Capocci, D. (2005) 'Neutrality of Market Neutral Funds', Working Paper, HEC - University of Liège, Liège.

18 Agarwal, V., Fung, W., Loon, Y. and Naik, N. Y. (2005) 'Risk and Return in Convertible Arbitrage: Evidence from the Convertible Bond Market', Working Paper, London Business School, London.

19 Brooks, C. and Kat, H. M. (2002) 'The Statistical Properties of Hedge Funds Index Returns and Their Implications for Investors', The Journal of Alternative Investments, Vol. 5, No. 2, pp. 26-44.

20 Fung, W. and Hsieh, D. A. (2002) 'Risk in FixedIncome Hedge Fund Styles', The Journal of Fixed Income, Vol. 12, No. 2 September, pp. 6-27.

21 Jaeger, L. and Wagner, C. (2005) 'Factor Modelling and Benchmarking of Hedge Funds: Can Passive Investments in Hedge Fund Strategies Deliver?' The Journal of Alternative Investments, Vol. 8, No. 3, pp. 9-36.

22 Duarte, J., Longstaff, F. A. and Yu, F. (2006) 'Risk and Return in Fixed Income Arbitrage: Nickels in Front of a Steamroller?', Working Paper, University of Washington.

23 Mitchell, M. and Pulvino, T. (2001) 'Characteristics of Risk and Return in Risk Arbitrage', The Journal of Finance, Vol. 56, No. 6, pp. 2135-2175.

24 Fung, W. and Hsieh, D. A. (2004a) 'Extracting Portable Alphas from Equity Long/Short Hedge Funds', Journal of Investment Management, Vol. 2, No. 4, pp. 1-19.

25 Schneeweis, T. and Spurgin, R. (1998) 'Multifactor Analysis of Hedge Fund, Managed Futures, and Mutual Fund Return and Risk Characteristics', The Journal of Alternative Investments, Vol. 1, No. 3, pp. 9-17.

26 Fung, W. and Hsieh, D. A. (2001) 'The Risk in Hedge Fund Strategies: Theory and Evidence from Trend Followers', Review of Financial Studies, Vol. 14, No. 2, pp. 313-341.

27 Kat, H. M. (2004) 'Managed Futures and Hedge Funds: A Match Made in Heaven', Journal of Investment Management, Vol. 2, No. 1, pp. 32-40.

28 Schneeweis, T. and Spurgin, R. (1997) 'Comparisons of Commodity and Managed Futures Benchmark Indices', The Journal of Derivatives, Vol. 4, No. 1, pp. 33-50.

29 Schneeweis, T. (1998) 'Dealing with Myths of Managed Futures', The Journal of Alternative Investments, Vol. 1, No. 2, pp. 9-18.

30 Lamm, R. M. (2004) 'The Answer to Your Dreams? Investment Implications of Positive Asymmetry in CTA Returns', The Journal of Alternative Investments, Vol. 7, No. 4, pp. 22-32.

31 Mandelbrot, B. (1963) 'The Variation of Certain Speculative Prices', Journal of Business, Vol. 36, No. 4, pp. 394-419.
32 Fama, E. F. (1965) 'The Behavior of Stock Market Prices', Journal of Business, Vol. 38, No. 1, pp. 34-105.

33 Bollerslev, T. and Melvin, M. (1994) 'Bid-Ask Spreads and the Volatility in the Foreign Exchange Market: An Empirical Analysis', Journal of International Economics, Vol. 36, No. 3-4, pp. 355-372.

34 Engle, R. F., Ito, T. and Lin, W. L. (1990) 'Meteor Showers or Heat Waves? Heteroscedastic Intra-Day Volatility in the Foreign Exchange Market', Econometrica, Vol. 58, No. 3, pp. 525-542.

35 Engle, R. F. and Mezrich, J. (1996) 'GARCH for Groups', Risk, Vol. 9, pp. 36-40.

36 We follow Engle (1982) in assuming the conditional distribution to be normal, but of course other distributions could also be applied. Engle, R. F. (1982) 'Autoregressive Conditional Heteroscedasticity with Estimates of the Variance of United Kingdom Inflation', Econometrica, Vol. 50, No. 4, pp. 987-1007.

37 In contrast to the $\operatorname{ARCH}(q)$ model which needs a long lag structure, the general version of Bollerslev (1986) permits a parsimonious parameterisation and a flexible lag structure. This property of conditional variances depending on past variances can also be observed in reality where stable and unstable periods alternate. Bollerslev, T. (1986) 'Generalized Autoregressive Conditional Heteroscedasticity', Journal of Econometrics, Vol. 31, No. 3, pp. 307-327.

38 See Theorem 1 in Bollerslev, T. (1986), p. 310.

39 Engle (1995) comments that the $\operatorname{GARCH}(1,1)$ is 'the leading generic model for almost all classes of returns', Engle, R. F., (ed.) (1995) 'ARCH Models', New York.

40 Bollerslev and Wooldridge (1992) show that the maximum likelihood estimates of the GARCH parameters under the assumption of normally distributed error terms is also consistent if the true distribution of the price innovations does not follow a Gaussian (normal) distribution. Bollerslev, T. and Wooldridge, J. M. (1992) 'Quasi-Maximum Likelihood Estimation and Inference in Dynamic Models with Time-Varying Covariances', Econometric Review, Vol. 11, No. 2, pp. 143-172.

41 Engle, R. F. and Ng, V. K. (1993) 'Measuring and Testing the Impact of News on Volatility', The Journal of Finance, Vol. 48, No. 5, pp. 1749-1778.

42 Sentana, E. (1995) 'Quadratic ARCH Models', Review of Economic Studies, Vol. 62, No. 213, pp. 639-661.

43 Nelson, D. B. (1991) 'Conditional Heteroskedasticity in Asset Returns: A New Approach', Econometrica, Vol. 59, No. 2, pp. 347-370.

44 The EGARCH model is a log transformation so a nonnegativity condition is not required.

45 Pagan, A. R and Schwert, G. W. (1990) 'Alternative Models for Conditional Stock Volatility', Journal of Econometrics, Vol. 45, No. 1-2, pp. 267-290. 
46 Haberfelner, F., Kaiser, D. G. and Kisling, K. (2006) 'Managed Accounts or The Price of Liquid and Transparent Hedge Fund and CTA Investing', in Gregoriou G.N. and Kaiser D.G. (eds.) Hedge Funds and Managed Futures - Handbook for Institutional Investors, Risk Books, London.

47 Fung, W and Hsieh, D. A. (2000) 'Performance Characteristics of Hedge Funds and Commodity Funds: Natural Versus Spurious Biases', Journal of Financial and Quantitative Analysis, Vol. 35, No. 3 September, pp. 291-307.
48 Fung, W. and Hsieh, D. A. (2004b) 'Hedge Fund Benchmarks: A Risk Based Approach', Financial Analyst, Vol. 60, No. 5, pp. 65-80.

49 The daily index data for the equity, bond and commodity markets, expressed in US dollar, were obtained from Thomson Financial Datastream.

50 For the methodology of unsmoothing hedge funds' time series see Brooks and Kat (2002).

51 Berndt, E. R., Hall, B. H., Hall, R. E. and Haussmann, J. A. (1974) 'Estimation and Inference in Nonlinear Structural Models', Annals of Economic and Social Measurement, Vol. 4 pp. 653-665. 